\title{
Neglected attention in apparent spatial compression
}

\author{
Paolo Bartolomeo $^{\text {a,b,* }}$, Marika Urbanski ${ }^{\text {a,c }}$, Sylvie Chokron ${ }^{\text {d,e }}$, Hanna Chainay ${ }^{\text {f }}$, \\ Christine Moroni ${ }^{\mathrm{g}}$, Eric Siéroff ${ }^{\mathrm{c}}$, Catherine Belin ${ }^{\mathrm{h}}$, Peter Halligan ${ }^{\mathrm{i}}$ \\ ${ }^{a}$ French Institute of Biomedical Research, INSERM EMI 007, Centre Paul Broca, 2ter rue d'Alésia, F-75014 Paris, France \\ ${ }^{\mathrm{b}}$ Fédération de Neurologie, Hôpital de la Salpêtrière, Paris, France \\ ${ }^{\mathrm{c}}$ Laboratoire de Psychologie Expérimentale, Université René Descartes (Paris 5), CNRS URA 8581, Paris, France \\ ${ }^{\mathrm{d}}$ Laboratoire de Psychologie Expérimentale, CNRS UMR 5105, Grenoble, France \\ e Fondation Ophtalmologique Rothschild, Paris, France \\ ${ }^{\mathrm{f}}$ Université de Bretagne Occidentale, Brest, France \\ ${ }^{\mathrm{g}}$ Laboratoire de Recherche sur l'Evaluation du Comportement et de l'Apprentissage, Université Charles de Gaulle, Lille, France \\ ${ }^{\mathrm{h}}$ Service de Neurologie, CHU Avicenne, AP-HP Paris, Bobigny, France \\ ${ }^{i}$ School of Psychology, Cardiff University, Cardiff, UK
}

Received 13 February 2003; received in revised form 18 June 2003; accepted 19 June 2003

\begin{abstract}
Halligan and Marshall [Cortex 27 (1991) 623] devised a new test to evaluate the hypothesis that in visual neglect, left space is systematically compressed rightwards. In the critical condition of the original study, rows of horizontally arranged numbers with a target arrow pointing to one of them from the opposite margin of the display were presented. When asked to verbally identify the number indicated by the arrow, a right brain-damaged patient with left neglect and hemianopia often indicated a number to the right of the target. The more the target was located on the left, the greater the response shift rightward, as if rightward compression were linearly proportional to the co-ordinates of Euclidian space. However, a possible alternative account could be that the patient's attention was attracted by the numbers located to the right of the target digit, thus biasing her responses toward numbers on the right. To explore this hypothesis, we asked normal participants and patients with right hemisphere lesions, with and without neglect or hemianopia, to mark on the margin of a sheet the approximate location indicated by an arrow situated on the opposite margin. In three different conditions, the arrow indicated either one of several numbers or lines in a row, or a blank location on the sheet margin. Only patients with left neglect, and especially those with associated hemianopia, deviated rightward, and then crucially only on those conditions where visible targets were present, consistent with the attentional bias account.
\end{abstract}

(c) 2003 Elsevier Ltd. All rights reserved.

Keywords: Unilateral neglect; Visual field defect; Space processing; Attentional and representational disorders

\section{Introduction}

Visual neglect is no longer considered a single monolithic disorder but rather a multiplicity of cognitive deficits that can collectively result in a lateralised disturbance of behavioural responses in different domains of space (Heilman, Watson, \& Valenstein, 2002; Vallar, 1998). Most neglect patients, however, might suffer from a combination of component (potentially dissociable) deficits (Driver \& Husain, 2002; Gainotti, D'Erme, \& Bartolomeo, 1991). In particular, the frequency and severity of attentional problems in neglect patients have been often underlined (Bartolomeo \& Chokron,

\footnotetext{
* Corresponding author. Tel.: +33-1-40-78-92-10; fax: +33-1-45-89-68-48/80-72-93/81-44-21.

E-mail address: paolo@broca.inserm.fr (P. Bartolomeo).
}

2001, 2002). Many neuropsychology texts present discussions of visual neglect in terms of an opposition between 'attentional' (e.g. Kinsbourne, 1993) and 'representational' accounts (e.g. Bisiach, 1993). While such an approach permits unification of a large and growing body of findingsthe adequacy of the explanation offered given the nature of the many different tasks involved can be simplistic and theoretically premature.

In considering left unilateral neglect as an impairment of mental representations, Bisiach and colleagues proposed that neglect patients suffered from a "representational scotoma" (Bisiach, Bulgarelli, Sterzi, \& Vallar, 1983, p. 36), or "a representational map reduced to one half" (Bisiach, Capitani, Luzzatti, \& Perani, 1981, p. 549). Another type of hypothetical representational impairment in neglect holds that space representation in neglect is characterised by some 
form of horizontal anisometry (Chatterjee, 2002; Chokron, Bernard, \& Imbert, 1997; Milner \& Harvey, 1995), where spatial co-ordinates progressively relax from the right to the left side. For example, Bisiach, Pizzamiglio, Nico, and Antonucci (1996) had neglect patients mark the left and right endpoints of a virtual horizontal line on the basis of a given midpoint. Patients misplaced the left endpoint leftwards (over-extension of left side), as if they had to travel further leftward than rightward to equalise the amount of perceived spatial extent (see also Chokron et al., 1997; Kerkhoff, 2000). Milner and Harvey (1995) maintained that neglect patients perceive left-sided horizontal physical segments as shorter than identical right-sided segments. However, Doricchi and Angelelli (1999) showed that only patients with an association of left neglect and hemianopia demonstrate this pattern of behaviour, suggesting that an interaction between cognitive and sensory disorders is necessary in order to produce the perceptual anisometry of horizontal extension.

In a different account, Halligan and Marshall (1991) suggested that space representation in left neglect was distorted - such that the left part was 'compressed' toward the right, similar to a shrunken scarf or a spring being compressed (see also Milner, 1987; Werth \& Poppel, 1988). Evidence in support of this account came from the pattern of performance of a single right brain-damaged patient with visual neglect and hemianopia. When on the critical horizontal conditions, the patient was presented with rows of numbers (from 1 to 15) either at the top or bottom of the display, and had to identify the number aligned with an arrow presented near the opposite margin of the display, she frequently indicated the number to the right of the target. The more the target was located on the left, the greater the response shift rightward. On the basis of this performance, Halligan and Marshall (1991) concluded that left space had been compressed rightward. However, as pointed out by Milner and Harvey (1995), a potential problem with this task is that the perception of the arrow location should be matched by similar changes in the perceived location of the targets. Thus, a putative spatial compression would affect both the arrow and the target location, and result in no apparent deviation in target identification. This possibility, however, prompts the question of why the patient described by Halligan and Marshall (1991) demonstrated a consistent rightward shift in target selection. A possible answer to this question could be that an attentional bias was at work, which determined neglect of the left-sided target stimuli and enhanced the relative salience of numbers located to the right of the target digit.

From a purely representational account of unilateral neglect (one where attentional factors were not held to play a contributing role), it would be relatively unimportant whether or not objects are presented in the non-neglected space, since it is the relative left part of the spatial representation (i.e. in this case of the page or TV screen) that is impaired irrespective of what happens in the other half. Per contra, some attentional accounts of neglect (e.g. Gainotti et al., 1991; Kinsbourne, 1993) have stressed that right-sided items are likely to attract patients' attention; the more objects presented on the 'unaffected' side, the greater the neglect (Mark, Kooistra, \& Heilman, 1988). In the present study, the aim was to explore the effect of the presence or absence of such competing stimuli on a task similar to that employed by Halligan and Marshall (1991), in the expectation that this additional experimental condition would help elucidate the effects of any attentional deficit.

Participants marked on a margin of the sheet the location indicated by an arrow situated on the opposite margin. In three different conditions, the arrow indicated either one of several numbers or lines in a row, or a blank location in a margin without any targets. The arrows were either presented on the top margin, pointing toward the bottom margin, or with the opposite spatial arrangement.

If a rightward attentional bias for objects is at work, then patients should show a differentially greater rightward deviation with competing targets. If, on the other hand, the representational problem consists of an anisometry of space representation with spatial co-ordinates progressively relaxing from the right to the left side on the horizontal plane (Bisiach et al., 1996), patients should show no deviation at all in either condition, because in performing the task they would proceed along the (presumably intact) radial dimension of spatial co-ordinates. Problems in programming left-directed arm movements (Bartolomeo, D'Erme, Perri, \& Gainotti, 1998; Heilman, Bowers, Coslett, Whelan, \& Watson, 1985; Mattingley, Bradshaw, \& Phillips, 1992) are also unlikely to influence the outcome of the present paradigm (like the original study by Halligan and Marshall (1991)) since all conditions required the same movements in the axial plane, without a major horizontal component. In any case, pre-motor deficits should not differentially affect performance in the three conditions of the task, which differ mainly in perceptual aspects and require similar motor responses.

A further issue of interest that could not be addressed in the single case study by Halligan and Marshall (1991) is the effect of left hemianopia. Hemianopia may interact with neglect in determining perceptual asymmetries (Doricchi \& Angelelli, 1999). Could this also apply to the 'spatial compression' task paradigm? The performance of patient P.P. (Halligan \& Marshall, 1991) cannot settle the issue, because she had an association of neglect and hemianopia. To explore the effects of hemianopia on this task performance, we also tested patients either with isolated neglect or hemianopia, or with an association of these two disorders. Normal participants and right brain-damaged patients without either neglect or hemianopia also participated to the study as control groups.

Finally, we aimed to explore not only accuracy of performance, but also its variability. This is an important but often neglected aspect of the clinical performance and has relevance for both attentional and representational accounts. Left neglect patients may show not only decreased performance 
for left-sided targets, but also increased variability for detection of these targets (Anderson, Mennemeier, \& Chatterjee, 2000). This may depend on the fact that left targets often, but not always, fail to capture patients' attention (Bartolomeo, Siéroff, Chokron, \& Decaix, 2001). In the few cases, in which attentional capture is adequate, patients may provide relatively good responses to these targets. This results in increased variability of response for these targets. Also normal participants show increased variability when their attention is diverted from the targets, both in terms of accuracy of response (Prinzmetal, Amiri, Allen, \& Edwards, 1998; Prinzmetal, Nwachuku, Bodanski, Blumenfeld, \& Shimizu, 1997; Prinzmetal \& Wilson, 1997) and of response time (Bartolomeo et al., 2001). Hence, increased variability of response again can be used to suggest that attention is being diverted from the current target. The finding of an increased variability of responses for left-sided targets in neglect patients may thus represent converging evidence for an attentional account of their performance on the spatial compression paradigm.

\section{Methods}

\subsection{Participants}

A total of 18 patients with unilateral lesions in the right hemisphere and eight age-matched controls consented to participate in the experiment. The presence and degree of neglect were evaluated using a test battery consisting of tasks of target cancellation, line bisection, and drawing copy (Bartolomeo \& Chokron, 1999). Individual results are shown in Table 1. All patients were examined for visual field defects using the confrontation task, which was administered following a previously described procedure (Bartolomeo \& Chokron, 1999; Gainotti et al., 1991). The patient was seated at a distance of about $1 \mathrm{~m}$ from the confronting examiner, and requested to fixate his or her gaze on the examiner's nose. Once fixation was stable, the examiner, who held his or her arms outstretched, briefly moved his or her fingers either in one hemifield or in both hemifields simultaneously. Patients were asked to report each movement of the examiner's fingers. In its basic form, the test consisted of six single unilateral stimuli (respectively delivered in left and right upper visual quadrants, left and right lower visual quadrants, and in left and right hemifields along the equatorial line) and six double simultaneous stimuli (two in the upper visual quadrants, two in the lower visual quadrants, and two on the equatorial line). The stimuli were delivered following a previously randomised sequence, which could be repeated up to three times. Patients were classified as suffering from left hemianopia when they did not detect the presence of the examiner's hand in their left visual field (from the extreme left to the midline, in both upper and lower quadrants). Patients perceiving left-sided stimuli only in one quadrant were excluded from the study. All but two patients showing hemianopia on confrontation underwent either Goldmann or Humphrey perimetry, or both. The two patients for whom perimetric data could not be obtained were $\mathrm{N}+\mathrm{H}+1$ and 3 (see Table 1). For all the other patients, the results of the perimetric tests were always consistent between them and with those obtained by confrontation, and demonstrated complete left homonymous hemianopia. Depending on the presence or absence of hemianopia and on their performance on the neglect screening, patients were divided into the following groups (see Table 1): patients with neglect and hemianopia $(\mathrm{N}+\mathrm{H}+; n=5)$, patients with neglect without hemianopia $(\mathrm{N}+\mathrm{H}-; n=5)$, patients with hemianopia without neglect $(\mathrm{N}-\mathrm{H}+; n=3)$, patients without either neglect or hemianopia $(\mathrm{N}-\mathrm{H}-; n=5)$.

\subsection{Stimuli}

Two classes of targets and one without any stimuli were constructed, each corresponding to one of the three experimental conditions: (1) "numbers", (2) "lines", and (3) "blank" (see Fig. 1).

Participants were presented with a $195 \mathrm{~mm} \times 195 \mathrm{~mm}$ white square centred on a horizontal A4 paper sheet. The contours of the square were black and $1 \mathrm{~mm}$ thick. All the stimuli were displayed within the square. Each square contained a single $15 \mathrm{~mm}$ long and $1 \mathrm{~mm}$ thick black vertical arrow. The arrow was printed $5 \mathrm{~mm}$ from the square's contour, either at its upper or bottom side, pointing to the opposite side. There were 12 possible positions of the arrow corresponding to a division of the side of the square into 12 equal intervals. The distance between intervals was $15 \mathrm{~mm}$. The first position was $15 \mathrm{~mm}$ from the left side of the square's contour. Consequently, there were 24 possible stimuli for each condition, 12 with the arrow at the upper side and 12 with the arrow at the bottom side of the square. In the "blank" condition, only the arrow was presented on the sheet. In the "lines" condition, the side of the square pointed at by the arrow was segmented at $5 \mathrm{~mm}$ intervals by 38 vertically-oriented black lines. The lines were $5 \mathrm{~mm}$ long and $1 \mathrm{~mm}$ thick. In the "numbers" condition each line was replaced by a single-digit number. Numbers were random and ranged between 1 and 9, with a different order for each arrow position. They were printed in 12-point Times New Roman style, bold type.

\subsection{Procedure}

Each participant performed all three experimental conditions. For each condition, each stimulus sheet was presented five times. Stimuli were presented in blocks of 60 stimuli; five presentations for each of the 12 horizontal arrow locations. This resulted in two blocks (one with up-pointing and one with down-pointing arrows) of 60 stimuli per condition. Upper and lower arrows were presented in separate blocks. The order of presentation was randomised within a block. The order of presentation of the blocks was 
Table 1

Demographical and clinical data for the four groups of patients

\begin{tabular}{|c|c|c|c|c|c|c|c|c|c|c|}
\hline Patient & $\begin{array}{l}\text { Gender/age/education } \\
\text { (years of schooling) }\end{array}$ & $\begin{array}{l}\text { Days from } \\
\text { lesion onset }\end{array}$ & Aetiology & Locus of lesion & $\begin{array}{l}\text { Line bisection } \\
\text { (\% deviation) }\end{array}$ & $\begin{array}{l}\text { Line cancellation } \\
(\max 30 / 30)\end{array}$ & $\begin{array}{l}\text { Bells cancellation } \\
(\max 15 / 15)\end{array}$ & $\begin{array}{l}\text { Letter cancellation } \\
(\max 30 / 30)\end{array}$ & $\begin{array}{l}\text { Overlapping } \\
\text { figures } \\
(\max 10 / 10)\end{array}$ & $\begin{array}{l}\text { Landscape } \\
\text { drawing } \\
(\max 6)\end{array}$ \\
\hline $\mathrm{N}+\mathrm{H}-1$ & $\mathrm{~F} / 72 / 14$ & 107 & Ischemic & Temporal parietal & +1.86 & $29 / 30$ & $10 / 14^{\mathrm{a}}$ & $26 / 29$ & $10 / 10$ & 5.5 \\
\hline $\mathrm{N}+\mathrm{H}-2$ & $\mathrm{M} / 44 / 17$ & 1470 & Ischemic & Parietal & $+13.46^{\mathrm{b}}$ & $29 / 30$ & $13 / 12$ & $30 / 28$ & $10 / 10$ & 5.5 \\
\hline $\mathrm{N}+\mathrm{H}-3$ & $\mathrm{~F} / 52 / 14$ & 110 & Hemorrhagic & $\begin{array}{l}\text { Internal capsule, } \\
\text { basal ganglia }\end{array}$ & +6.26 & $30 / 30$ & $11 / 15^{\mathrm{a}}$ & $27 / 28$ & $10 / 10$ & 6 \\
\hline $\mathrm{N}+\mathrm{H}-4$ & $\mathrm{M} / 48 / 7$ & 30 & Ischemic & Temporal parietal & +10.44 & - & $9 / 14^{\mathrm{a}}$ & $25 / 29$ & $10 / 10$ & 5 \\
\hline $\mathrm{N}+\mathrm{H}-5$ & $\mathrm{M} / 73 / 6$ & 5 & Ischemic & Temporal parietal & +8.82 & $27 / 30^{\mathrm{c}}$ & $8 / 14^{\mathrm{a}}$ & $25 / 30$ & - & 6 \\
\hline $\mathrm{N}+\mathrm{H}+1$ & $\mathrm{M} / 57 / 10$ & 191 & Hemorrhagic & $\begin{array}{l}\text { Basal ganglia, } \\
\text { temporal occipital }\end{array}$ & +2.78 & $28 / 30^{\mathrm{c}}$ & $0 / 13^{\mathrm{a}}$ & $0 / 22$ & $8 / 10^{c}$ & 3 \\
\hline $\mathrm{N}+\mathrm{H}+2$ & $\mathrm{M} / 59 / 12$ & 207 & Ischemic & Occipital & $+52.90^{\mathrm{b}}$ & $30 / 30$ & $10 / 9$ & $28 / 28$ & $10 / 10$ & 4 \\
\hline $\mathrm{N}+\mathrm{H}+3$ & $\mathrm{M} / 48 / 14$ & 127 & Hematoma & Temporal parietal & $+32.71^{\mathrm{b}}$ & $0 / 19^{c}$ & $0 / 8^{\mathrm{a}}$ & $6 / 26$ & $6 / 10^{c}$ & 2 \\
\hline $\mathrm{N}+\mathrm{H}+4$ & $\mathrm{M} / 43 / 12$ & 185 & Neoplastic & Temporal parietal & -6.73 & $30 / 30$ & $13 / 15$ & $27 / 30$ & $10 / 10$ & 5.5 \\
\hline $\mathrm{N}+\mathrm{H}+5$ & $\mathrm{M} / 52 / 14$ & 137 & Ischemic & $\begin{array}{l}\text { Occipital } \\
\text { temporal, parietal } \\
\text { (subcortical) }\end{array}$ & -6.03 & $29 / 30$ & $0 / 15^{\mathrm{a}}$ & $13 / 28$ & $9 / 10$ & 3.5 \\
\hline $\mathrm{N}-\mathrm{H}-1$ & $\mathrm{M} / 39 / 17$ & 73 & Hemorrhagic & Frontal & -0.93 & $30 / 29$ & $14 / 14$ & $29 / 30$ & $10 / 10$ & 6 \\
\hline $\mathrm{N}-\mathrm{H}-2$ & $\mathrm{M} / 54 / 10$ & 55 & Ischemic & Frontal parietal & +9.51 & $30 / 30$ & $13 / 13$ & $23 / 21$ & $10 / 10$ & 6 \\
\hline $\mathrm{N}-\mathrm{H}-3$ & $\mathrm{M} / 45 / 14$ & 815 & Ischemic & Temporal parietal & -12.63 & $30 / 30$ & $14 / 14$ & $26 / 26$ & $10 / 10$ & 6 \\
\hline $\mathrm{N}-\mathrm{H}-4$ & $\mathrm{M} / 49 / 12$ & 162 & Ischemic & Temporal occipital & -3.25 & $29 / 30$ & $14 / 15$ & $30 / 30$ & $10 / 10$ & 6 \\
\hline $\mathrm{N}-\mathrm{H}-5$ & $\mathrm{M} / 62 / 17$ & 176 & Hemorrhagic & Frontal parietal & +0.46 & $30 / 30$ & $14 / 14$ & $28 / 26$ & $10 / 10$ & 6 \\
\hline $\mathrm{N}-\mathrm{H}+1$ & $\mathrm{~F} / 41 / 15$ & 1457 & Hemorrhagic & Occipital parietal & -4.61 & $30 / 30$ & $15 / 15$ & - & $10 / 10$ & 6 \\
\hline $\mathrm{N}-\mathrm{H}+2$ & $F / 22 / 12$ & 569 & Ischemic & Occipital & -12.06 & - & $15 / 15$ & - & - & - \\
\hline $\mathrm{N}-\mathrm{H}+3$ & $\mathrm{M} / 68 / 7$ & 31 & Hemorrhagic & Temporal occipital & -4.50 & $30 / 30$ & $14 / 15$ & $29 / 29$ & $10 / 10$ & 6 \\
\hline
\end{tabular}

Performance on the neglect battery is also shown. -, Missing data. For line bisection, + indicates rightward deviation and - indicates leftward deviation. For cancellation tests, left/right correct responses are reported. The landscape drawing, consisting of a central house with two trees on each side, was scored by assigning two points to the house and one point to each tree completely copied. Footnotes (a-c) indicate pathological performance for standardised tests.

${ }^{a}$ Left-right difference of omissions beyond the 95th percentile of normal performance (Rousseaux et al., 2001; test originally described in Gauthier, Dehaut, \& Joanette, 1989).

${ }^{\mathrm{b}}$ Rightward deviation larger than 2S.D. from the mean performance of 30 normal individuals (Bartolomeo et al., 1994).

${ }^{\mathrm{c}}$ The same group of normal individuals never omitted more than one item on these tasks. 


\section{numbers}

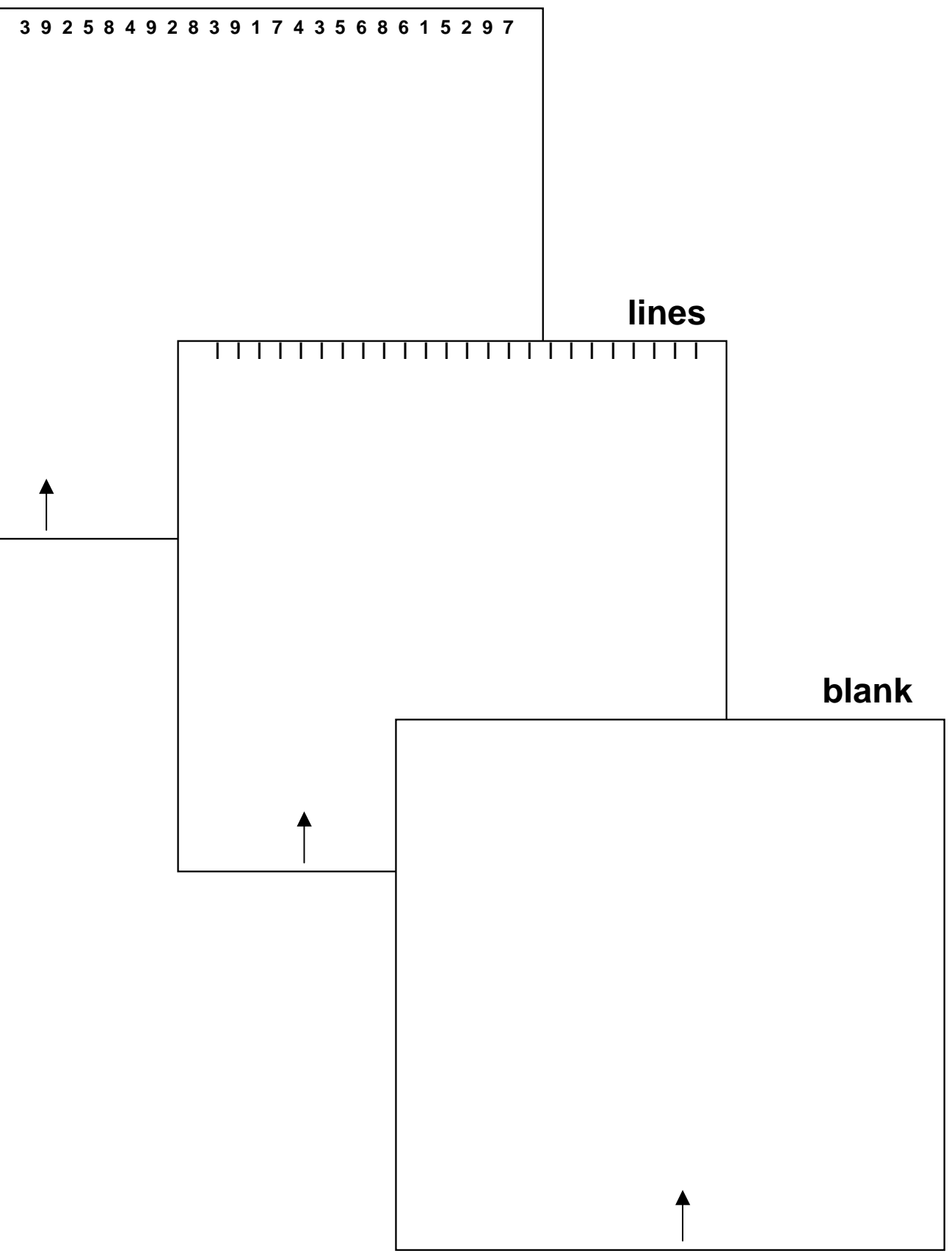

Fig. 1. Example of items from the three experimental conditions (the stimuli are fewer than those actually presented and are not drawn to scale).

counterbalanced across participants. For each stimulus, participants were requested to mark with a fluorescent marker the position indicated by the arrow on the opposite side of the square. Before administering the experimental trials the experimenter ensured that each participants had understood the task instructions. To this end, each participant had three practice trials or more as needed. There was no time limit. In total, the whole task took 2-3 h (depending on individual participants), and this was often divided in two or three test sessions, separated by a maximum of 1 week interval. Participants examined in two sessions received three blocks per session; participants examined in three sessions received two blocks per session. Deviation from the target was measured in $\mathrm{mm}$. To ensure a uniform measurement procedure across the different conditions, after the task was performed the sheet margin of the items for the blank condition was horizontally divided in $5 \mathrm{~mm}$ steps, corresponding to the locations of the targets in the other conditions. Deviation 
was then measured to the nearest $5 \mathrm{~mm}$ division. Rightward deviations were given a plus sign and leftward deviations carried a minus sign.

\section{Results}

\subsection{Accuracy}

Controls performed the task accurately, with more than $97 \%$ of their performance being situated within $5 \mathrm{~mm}$ left or right of the target (mean $\pm 95 \%$ confidence interval, $0.01 \pm 0.17 \mathrm{~mm}$ ), thus indicating that the task was relatively easy to perform (see also Halligan \& Marshall, 1991). A repeated-measures analysis of variance (ANOVA) was performed on the accuracy data with group $(\mathrm{N}-\mathrm{H}-, \mathrm{N}+\mathrm{H}-$, $\mathrm{N}+\mathrm{H}+, \mathrm{N}-\mathrm{H}+$ and controls) as between factor and condition (blank, lines, numbers), horizontal arrow position (1-12, from the left to the right), and vertical arrow position (up-pointing or down-pointing) as within factors. There was an effect of group, $F(4,21)=19.77, P<0.0001$, because $\mathrm{N}+\mathrm{H}+$ and $\mathrm{N}+\mathrm{H}-$ deviated rightward (by 5.56 and $1.37 \mathrm{~mm}$ on average, respectively), whereas the other groups shifted leftward of less than $1 \mathrm{~mm}$ on average. On post hoc tests (Fisher's PLSD), the $\mathrm{N}+\mathrm{H}+$ group differed from all the other groups (all $P<0.0001$ ); the $\mathrm{N}+\mathrm{H}-$ group differed only from the $\mathrm{N}-\mathrm{H}-$ group, $P=0.018$. Importantly, there was an effect of the condition, $F(2,42)=24.75, P<$ 0.001 , in the direction predicted by the attentional account; there was less rightward deviation in the blank condition than in the conditions with numbers or lines, $P<0.001$; these two last conditions did not differ from each other. Again as predicted by the attentional account, the group and condition factors interacted, $F(8,42)=9.17, P<0.0001$; only neglect patients (and especially those with neglect and hemianopia) deviated in conditions with visual targets (Fig. 2).

The relative horizontal position of the arrow influenced performance, $F(11,231)=21.09, P<0.0001$, and interacted with the group, $F(44,231)=11.19, P<0.0001$, with the condition, $F(22,462)=2.56, P=0.0001$, and with both group and condition, $F(88,462)=1.61, P=0.001$. These interactions reflected the fact that neglect patients showed a gradient-shaped performance, with greater rightward deviation when the arrow was located more to the left (see Fig. 2), similar to that found in P.P.'s performance (Halligan \& Marshall, 1991). The interactions again involved the task condition because the gradient was particularly evident in the conditions with visual targets. Although there was no influence of the vertical position of the arrow on overall performance, $F<1$, this factor interacted with the group, $F(4,21)=4.00, P=0.01$, with the horizontal position, $F(11,231)=13.22, P<0.001$, and with both horizontal position and group, $F(88,462)=2.72, P<0.001$. This came about because only brain-damaged patients, and not normal participants, showed a vertical-horizontal in- teraction (see below for a description of this interaction in neglect patients).

To follow up these results, separate ANOVAs were conducted on each of the two groups of neglect patients (with or without hemianopia). For $\mathrm{N}+\mathrm{H}+$ patients, the analysis confirmed that the conditions with visual targets evoked more rightward deviation than that without targets, $F(2,8)=25.88, P=0.0003$ (blank versus lines or numbers, $P<0.0005$; lines versus numbers, ns). The deviation varied with the horizontal position of the arrow, $F(11,44)=26.70, P<0.0001$, because it was maximal with the arrow on the left side and decreased gradually with more rightward positions (see Fig. 2E). This effect interacted with the condition, $F(22,88)=2.86, P=0.0003$, because it was most evident in the conditions with visual targets. The vertical position of the arrow interacted with the horizontal position, $F(11,44)=4.80, P<0.0001$, because down-pointing arrows evoked gradients with steeper slopes than up-pointing arrows. Linear models provided an adequate description of data from the conditions with visual targets, as shown by regression analyses with the objective horizontal position as independent variable and the deviation from the target as dependent variable, which explained from 39 to $97 \%$ of the total variance, $F(1,11)>6.33$, all $P<0.05$.

Despite the fact that $\mathrm{N}+\mathrm{H}-$ patients showed a lesser rightward deviation than $\mathrm{N}+\mathrm{H}+$ patients (see Fig. 2), they presented a qualitatively similar pattern of effects and interactions. The presence of visual targets increased the shift, $F(2,4)=4.93, P=0.04$ (although on paired comparisons the blank versus lines contrast only approached significance, $P=0.0676$; blank versus numbers, $P=0.015$; lines versus numbers, ns). The horizontal location of the arrow again affected performance, $F(11,44)=7.57, P<0.0001$, and interacted with the vertical position, $F(11,44)=6.96$, $P<0.0001$, because down-pointing arrows were associated with gradients of performance with steeper slopes than up-pointing arrows.

In contrast to the generally negative slopes observed for neglect patients, which reflected a gradient of performance similar to that shown by P.P. (Halligan \& Marshall, 1991), the other groups of participants usually showed positive slopes when their errors were regressed on the horizontal position of the arrow. In descriptive terms, the non-neglect participants slightly deviated leftward with left-sided arrows (except for the leftmost position), and tended to become more and more accurate as the arrow moved towards the right (see Fig. 2A-C). However, with a few exceptions, for the non-neglect groups, linear models accounted for less than $33 \%$ of the variance, $F(1,11)<4.80$, ns.

\subsection{Variability}

We calculated the within-subjects S.D. for each position of the arrow and conducted a repeated-measures ANOVA on these data with group $(\mathrm{N}-\mathrm{H}-, \mathrm{N}+\mathrm{H}-, \mathrm{N}+\mathrm{H}+$, 


\section{Normal controls}

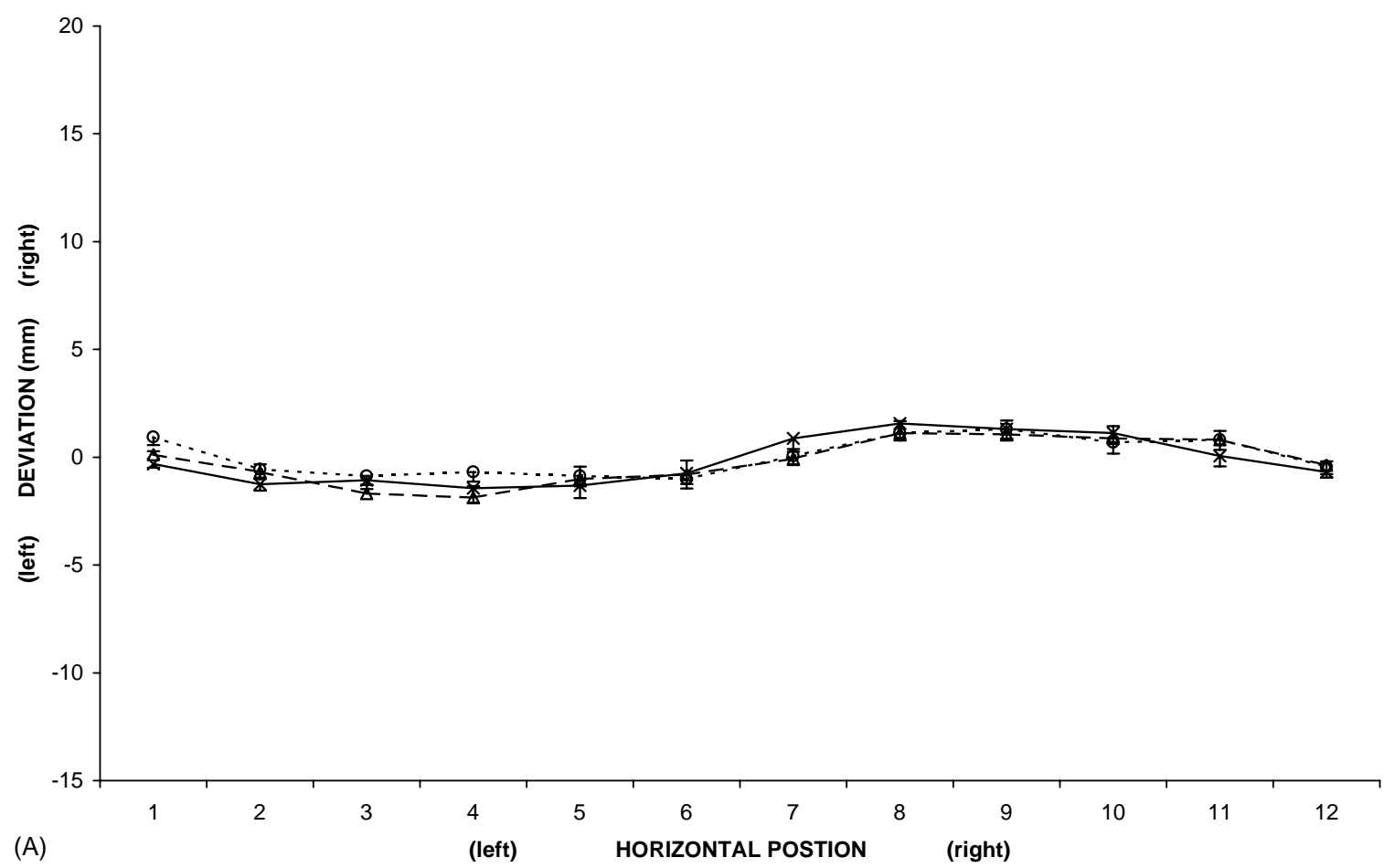

N-H-

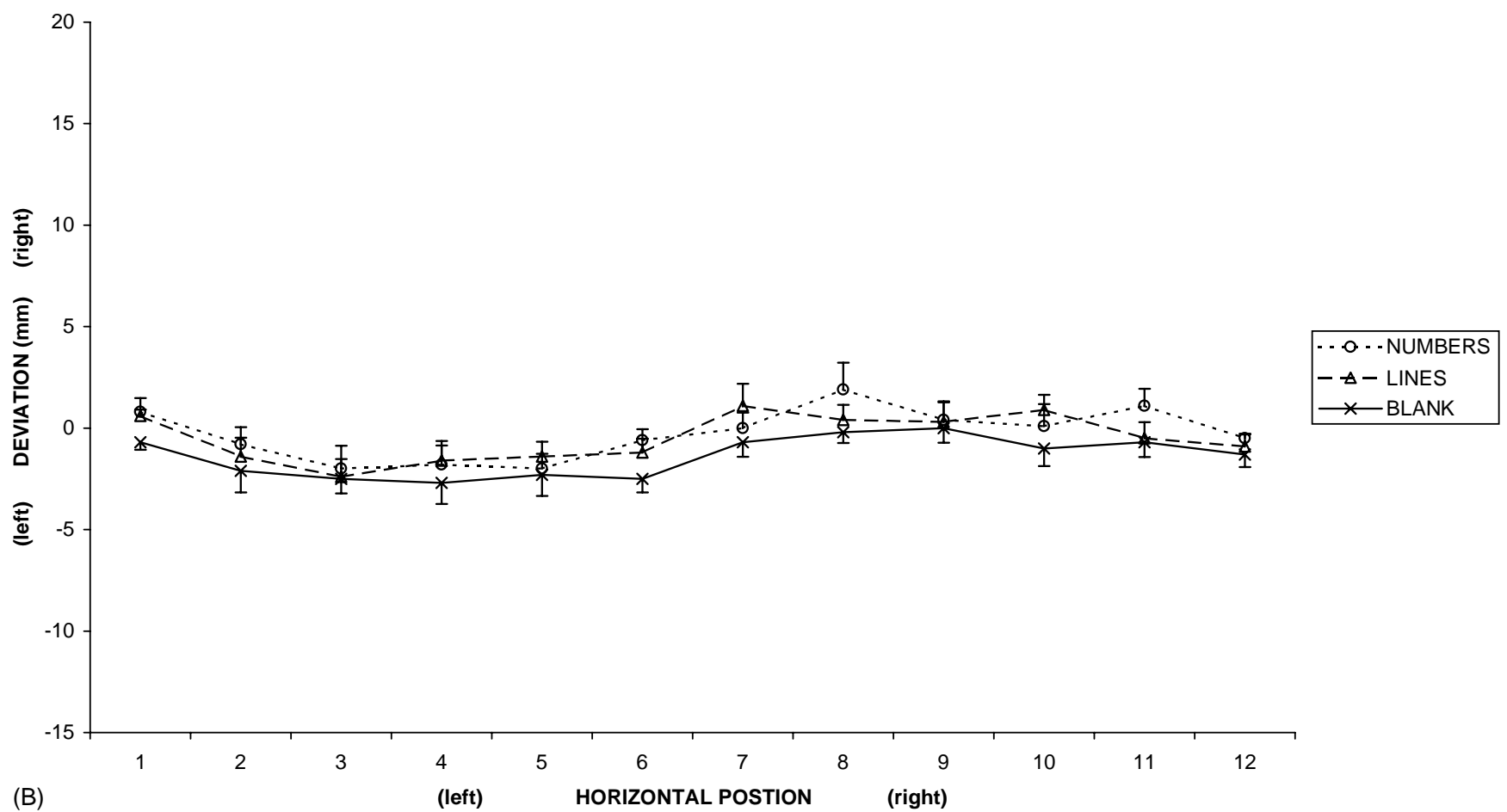

Fig. 2. (A-E) Performance of the different groups of participants as a function of task condition and horizontal arrow position. Error bars: 1S.E. 


\section{N-H+}

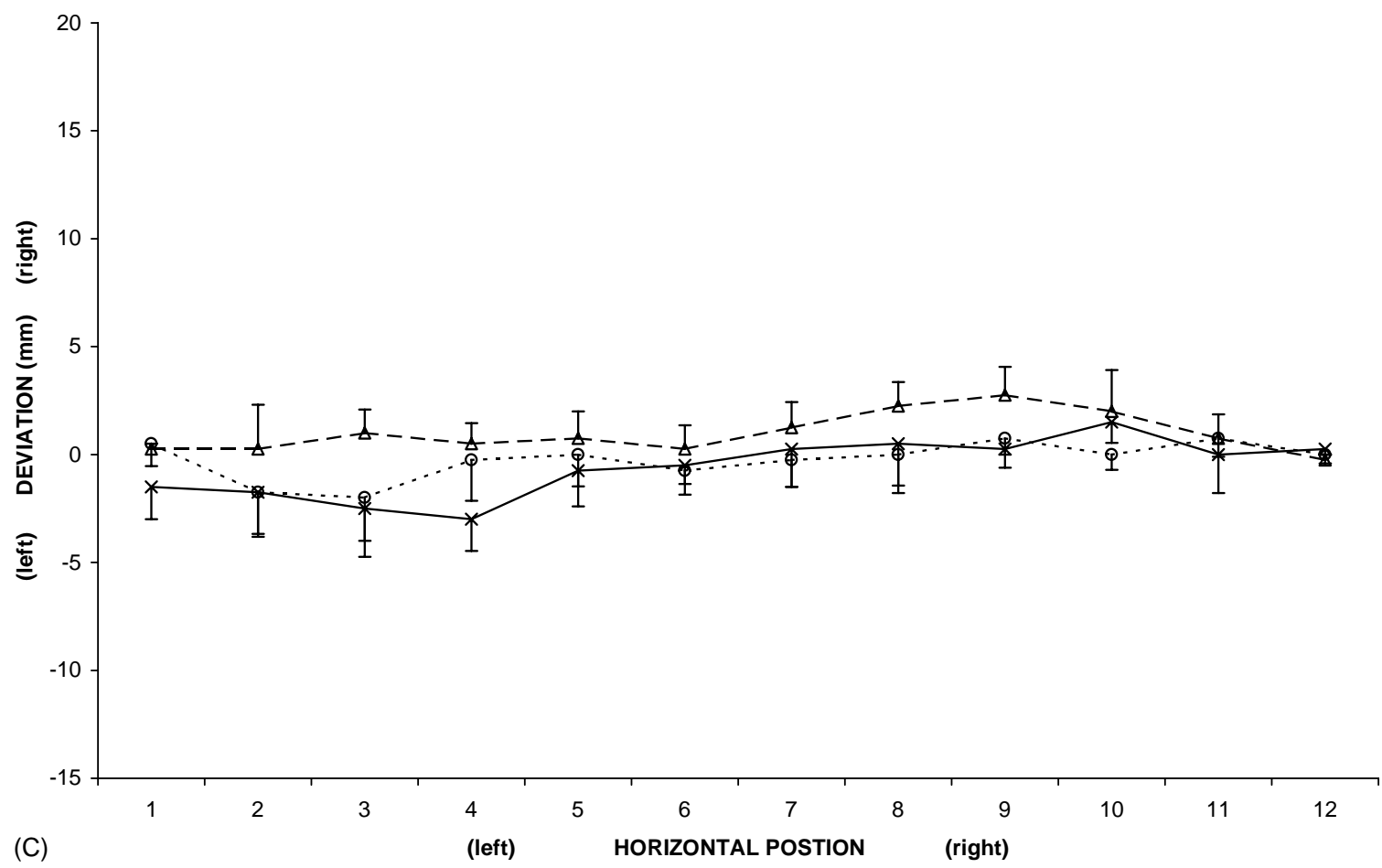

$\cdots:-$ NUMBERS
$-\Delta-$ LINES
$x-$ BLANK

$\mathrm{N}+\mathrm{H}-$

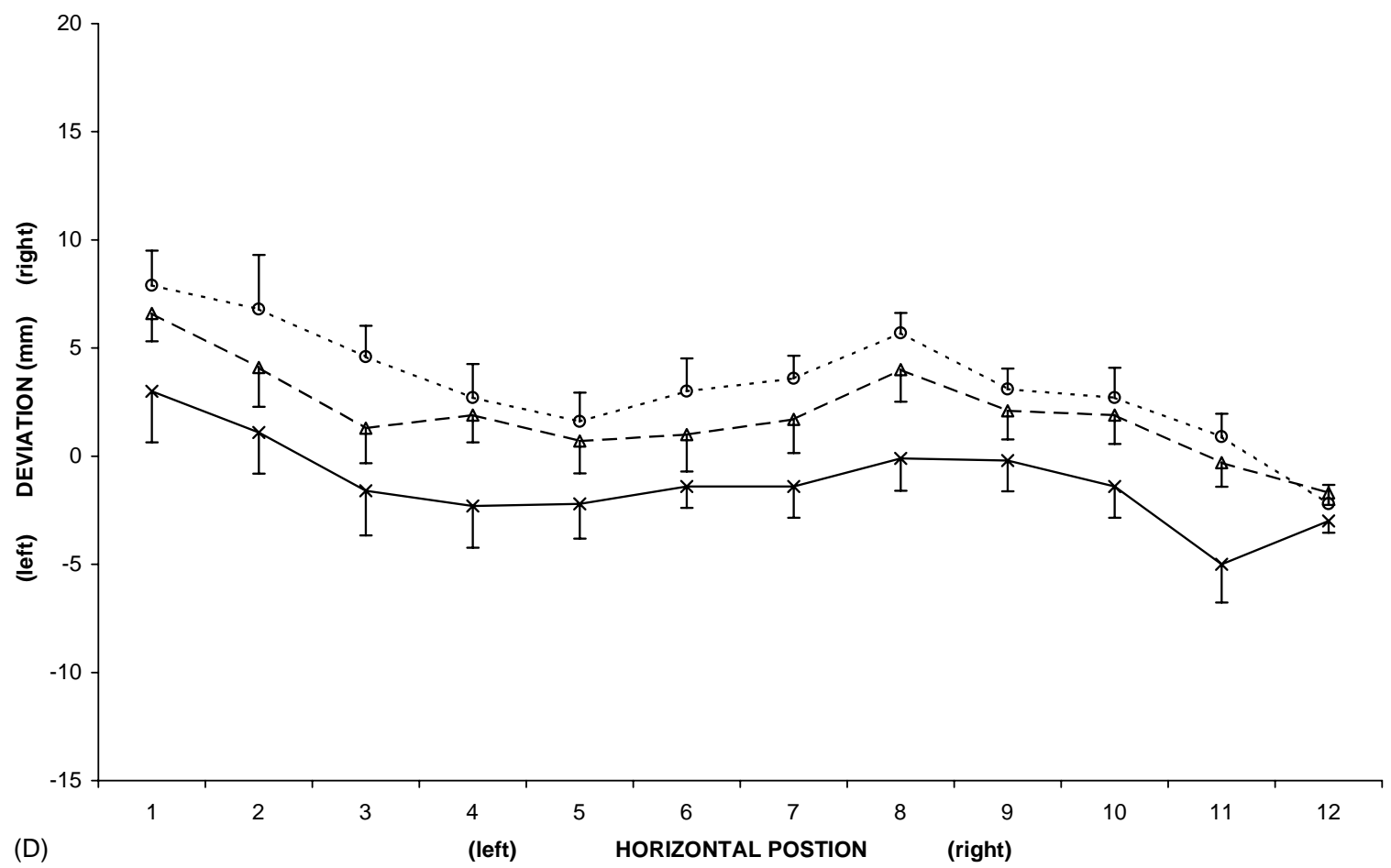

Fig. 2. (Continued) 
$\mathrm{N}+\mathrm{H}+$

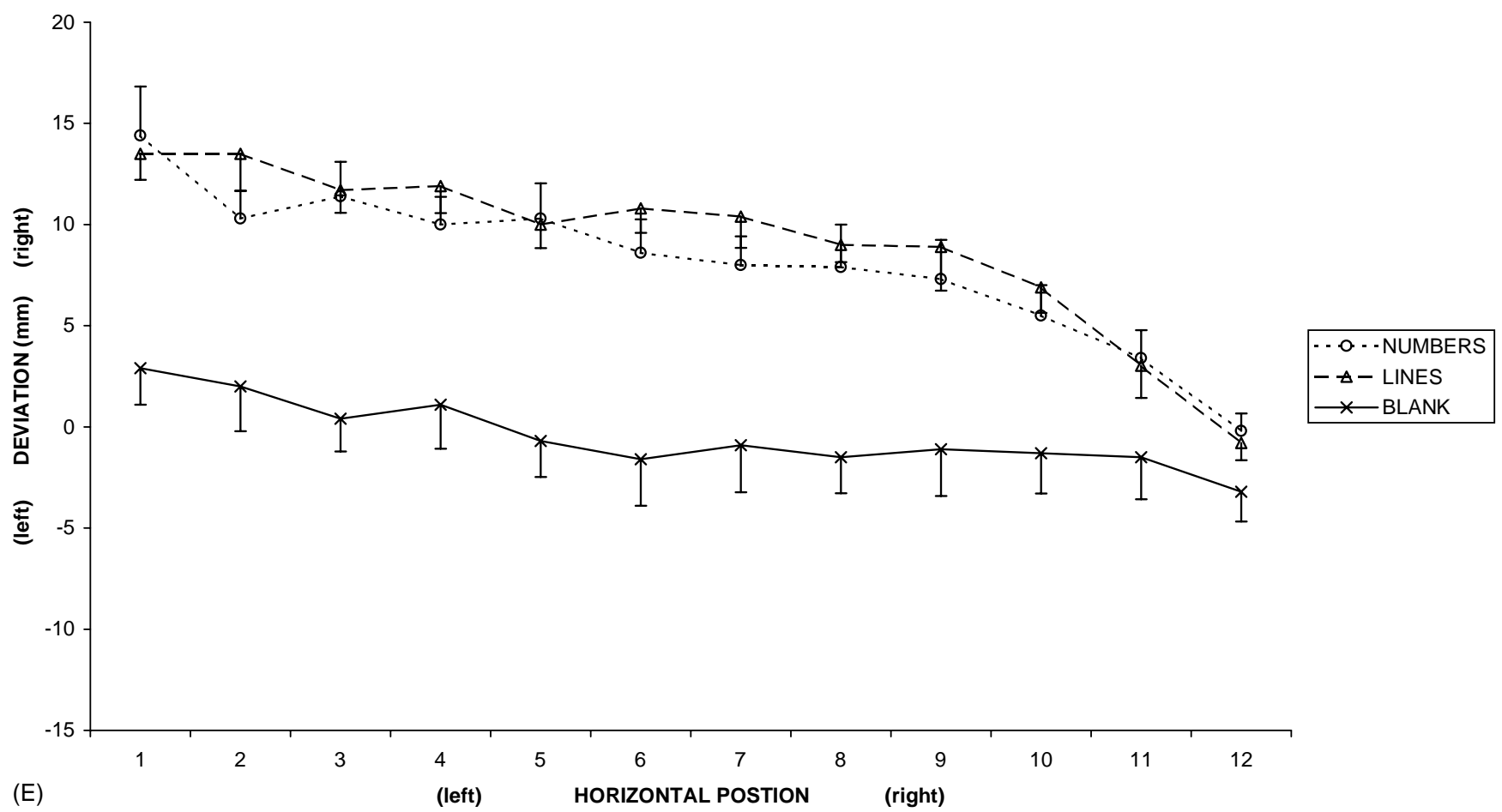

Fig. 2. (Continued).

$\mathrm{N}-\mathrm{H}+$ and controls) as between factor and condition (numbers, lines, blank), horizontal position (1-12), and vertical position (up-pointing, down-pointing) as within factors. Average S.D.s for each group were as follows: controls, $1.78 \mathrm{~mm}, \mathrm{~N}-\mathrm{H}-, 2.48 \mathrm{~mm} ; \mathrm{N}-\mathrm{H}+, 1.47 \mathrm{~mm}$; $\mathrm{N}+\mathrm{H}-, 3.87 \mathrm{~mm} ; \mathrm{N}+\mathrm{H}+, 4.47 \mathrm{~mm}$. There was an effect of the group, $F(4,21)=16.85, P<0.0001$, because neglect patients had more variable performance than each of the other groups (Fisher's PLSD, all $P<0.01$ ); no difference in variability emerged between neglect patients with or without hemianopia. The horizontal position of the arrow influenced variability of performance, $F(11,231)=45.88$, $P<0.0001$, because there was progressively less variability with targets presented from the left to the right side. This was only true for neglect patients, which resulted in an interaction with the group factor, $F(44,231)=8.91$, $P<0.0001$. The task condition had no effect on overall variability, $F<1$, but interacted with the vertical position of the arrow, $F(2,42)=27.84, P=0.005$, and with both the vertical and the horizontal positions, $F(22,462)=5.54$, $P=0.04$. These interactions originated from a particularly high variability of performance for numbers presented at the bottom-left part of the sheet.

Regression analyses showed that variability of performance decreased monotonically from the left to the right only for the $\mathrm{N}+\mathrm{H}+$ group, and then only on the conditions with visual targets.

\section{Discussion}

This study was inspired by the results reported in a single case study by Halligan and Marshall (1991), where the findings were used to support the case that a systematic compression of space was responsible for the patients' neglect. These authors found that their patient with left-sided neglect and hemianopia deviated significantly rightward when she was required to indicate the number of a horizontal array which has been designated by a vertical arrow located on the opposite side of the display. The main aims of the current study were to confirm and replicate the original findings in a large group study and establish whether the original account could be explained by attentional deficits. We confirmed a rightward deviation similar to that described by Halligan and Marshall (1991), i.e. a lateral gradient of performance with decreasing rightward deviation from the left to the right side of the display. Significantly, however, the rightward shift was present only when the target had to be selected from among other physical candidates (lines or numbers). Patients with left neglect and hemianopia demonstrated the most severe rightward shift, whereas neglect patients without hemianopia showed milder deviations. Thus, it appears that the pattern of results can be best predicted by a hypothesis that assumes a biased orienting of attention. 
On this attentional account, the patients deviate rightward in conditions with visible targets because items on the right side of the target attract their attention, and as such present as the more plausible candidate for response.

The alternative hypotheses mentioned in the introduction, such as failure to properly represent left-sided space or directional motor deficits, fail to fully capture the crucial difference between target-present and target-absent conditions. A directional motor deficit affecting the right arm could be consistent with the present results if it was hypothesised that only leftward movements aimed at left-sided visual targets would be compromised by the putative deficit and not left-directed movements per se. Although such a possibility has been suggested (Mattingley, Husain, Rorden, Kennard, \& Driver, 1998), it does not seem to correspond to the original definition of limb directional hypokinesia as a problem related to movement direction (Heilman et al., 1985). Note, moreover, that such an account would have left unexplained the performance of patient P.P. in the original study by Halligan and Marshall (1991), where the task was to verbally identify a visual target, without the need of producing any arm movement. A further possibility could be that, when performing the present task, neglect patients' gaze drifted rightward when moving from one horizontal side of the sheet to the other. Neglect patients are indeed prone to orient their gaze towards ipsilesional visual targets (Gainotti et al., 1991). However, this possibility would not be inconsistent with the attentional account, because gaze shifts are usually preceded by analogous shifts in spatial attention (Hoffman \& Subramaniam, 1995; Kowler, Anderson, Dosher, \& Blaser, 1995; Shepherd, Findlay, \& Hockey, 1986). Thus, a rightward ocular drift might well have resulted from patients' attention being attracted by rightward targets. Our crucial result that no deviation was present in the absence of visible targets seems inconsistent with any account based on a purely directional bias of gaze shifts, such as, for example, the possibility that patients produced hypometric leftward saccades (Butter, Rapcsak, Watson, \& Heilman, 1988).

The interaction between the horizontal and the vertical positions of the arrow, with top arrows pointing to bottom targets that engendered steeper gradients of performance than the opposite assignment, is more difficult to interpret. It is, however, broadly consistent with the performance of patient P.P. (Halligan \& Marshall, 1991), who presented slightly steeper slopes with bottom targets than with top targets. The steeper slopes that we observed with down-pointing arrows reflect more rightward deviation for left-bottom targets than for left-top targets. This is remindful of the fact that in cancellation tasks, neglect patients often omit more targets in the left-inferior quadrant than in the left-superior quadrant (Chatterjee, Thompson, \& Ricci, 1999; Halligan \& Marshall, 1989; Mark \& Heilman, 1997). This radial asymmetry of performance may represent a lesional correlate of a possible specialisation of the parietal lobe for operations directed in near and lower space (Previc, 1990).
Our results on accuracy of response were paralleled by analogous findings when variability of response was used as a dependent variable. In patients with neglect and hemianopia, we found a gradient of variability of response, with maximal variability for left-sided targets and a gradual decrease toward the right. An analogous gradient was observed in response time studies with neglect patients (Anderson et al., 2000). Increased variability of response is often observed when attention tends to be diverted from the target (Bartolomeo et al., 2001; Prinzmetal et al., 1997, 1998; Prinzmetal \& Wilson, 1997). A possible explanation of this effect relies on the probabilistic nature of attentional orienting. If left neglect patients tend to orient their attention rightward, left targets will often, but not always, fail to capture patients' attention. This will result in normal or near-normal performance on those rare trials in which a left target does capture patients' attention. The coexistence of relatively accurate performance for attended left targets with impaired performance for non-attended left targets could engender the observed space-based variability in neglect. Thus, the present results on variability of performance are again consistent with the hypothesis that patients' attention was biased towards the right side when they performed the spatial compression task.

There is compelling evidence for the important role that right visual stimuli can make in exacerbating neglect behaviour (Chokron, Colliot, \& Bartolomeo, in press; De Renzi, Gentilini, Faglioni, \& Barbieri, 1989; Gainotti et al., 1991; Kinsbourne, 1970, 1993; Marshall \& Halligan, 1989). Mark et al. (1988) required neglect patients to draw on targets scattered on a sheet with a pencil mark or to erase them, found more left omission in the 'draw' than in the 'erase' condition, and concluded that right-sided (cancelled) targets continued to attract patients' attention, thereby increasing left neglect. In a Posner-type reaction time paradigm (see Posner, Walker, Friedrich, \& Rafal, 1984), D'Erme, Robertson, Bartolomeo, Daniele, and Gainotti (1992) found slower responses to left-sided targets when targets occurred in one of two bilateral boxes than when they occurred without boxes, as if the right-sided box again attracted patient's attention. Bartolomeo, D'Erme, and Gainotti (1994) explored visual neglect and imaginal neglect (i.e. neglect during description from memory of known places, see Bisiach \& Luzzatti, 1978) in the same patients and found that neglect was more frequent and severe in the visual than in the imaginal domain. Again, it is possible that right-sided visual targets attracted patients' attention in the visual condition, but not in the imaginal condition. Our results are consistent with these earlier proposals, and also help extend these by showing that rightward bias after left neglect may be sufficiently powerful to influence perceptual judgements tasks (radial imagined extension of an arrow) that do not explicitly involve lateral exploration of space.

In the present study, we confirmed Halligan and Marshall's (1991) observation of a spatial gradient of response; in neglect patients, the more leftward the arrow, the 
more rightward-deviated the response. This gradient could result from the fact that the more leftward the stimulus arrow was (relative to the centre of the page), the greater the number of potential stimulus items were on the right of the target. This would increase the possibility of choosing one of these right distracters.

Our finding that the rightward deviation was more severe in patients with both neglect and hemianopia than in patients with neglect alone, is again consistent with previous observations reporting analogous differences in performance with other experimental paradigms (Daini, Angelelli, Antonucci, Cappa, \& Vallar, 2002; D’Erme, De Bonis, \& Gainotti, 1987; Doricchi \& Angelelli, 1999). If the chosen target in our task was the result of competition between other potential targets, and this competition was attentionally rightward-biased due to neglect, then the co-presence of a left hemianopia might be expected to reinforce this rightward shift by completely suppressing the contribution of items to the left of fixation. An attentional component seems nonetheless necessary to produce much of the observed biased performance: patients with hemianopia but without neglect did not show any consistent deviation on our task. In patients with neglect and hemianopia, left neglect was often more severe than in patients with neglect alone (see Table 1), perhaps because $\mathrm{N}+\mathrm{H}+$ patients were more likely to have larger lesions than $\mathrm{N}+\mathrm{H}-$ patients. This raises the possibility that the pattern of results obtained were in fact determined by the severity of neglect alone, with more severe patients deviating more than milder patients, rather than by the association of neglect plus hemianopia. Although the present results cannot be regarded as conclusive concerning this possibility, the performance of a patient in the $\mathrm{N}+\mathrm{H}+$ group argues against this interpretation. Patient 4 had only mild signs of neglect in association with left hemianopia (see Table 1), but showed a substantial rightward deviation in the lines and numbers conditions ( 6.05 and $5.13 \mathrm{~mm}$ on average, respectively), suggesting that it was the association of neglect and hemianopia, and not the extent of neglect, that was responsible for the increased shift.

The detrimental effect of hemianopia in neglect patients' performance on the present task is reminiscent of the similar effect of visual field defect on line bisection, a widely used diagnostic test for neglect. Despite some negative results (Halligan, Marshall, \& Wade, 1990), and the fact that patients with visual field defects reliably produce a contralesional bias on line bisection (Barton \& Black, 1998; Fuchs, 1920), it has been repeatedly shown that patients with neglect and hemianopia show a greater rightward deviation on line bisection than patients with neglect only (Daini et al., 2002; D'Erme et al., 1987; Doricchi \& Angelelli, 1999). Our finding that the presence of non-relevant (right-sided) target stimuli may produce a rightward bias in perceptual judgements suggests a possible shared account for this pattern of performance with line bisection. In line bisection, it has been hypothesised that the subjective midpoint is treated as a virtual target (Halligan \& Marshall, 1998), chosen from several possible candidates (other points of the line), on the basis of the relative salience of the two segments. Under the influence of left neglect, this perceptual decision is biased to the right and this pathological bias may be responsible for the present results on our compression task. The presence of a concurrent left hemianopia would therefore increase the likelihood that left-sided targets would be not be chosen, all of which would contribute to a performance reflecting a greater rightward bias of attention. ${ }^{1}$

Our results also suggest the need to reappraise other findings previously ascribed to the operations of purely representational mechanisms. For example, Ricci, Calhoun, $\&$ Chatterjee (2000) recently argued that a limitation in patients' ability to represent horizontal magnitudes determines the length effect in line bisection (that is, the fact that left neglect patients bisect longer lines further to the right than shorter lines), and denied that this effect could result from an attentional bias (longer lines extend further ipsilesionally and thus shift patients' attention rightward to a greater extent than shorter lines). Ricci et al. took ingeniously advantage of the Oppel-Kundt illusion, which makes normal subjects perceive as longer lines made of several short segments, compared with lines of equal physical length, but made of a lesser number of longer segments. They constructed two classes of $200 \mathrm{~mm}$ long lines, either made of shorter or of longer segments. When three left neglect patients were asked to bisect these lines, their rightward error was greater for the lines made of shorter segments than for the lines made of longer segments. Because the physical length of the lines was the same, the authors concluded that patients' performance was determined by their (illusory) internal representation of the lines, and cannot be explained by attentional mechanisms directed to the external stimulus. However, our present results suggest that an attentional account is both possible and likely. Despite the instructions to "treat the stimuli as if they were solid lines" (p. 674), Ricci et al.'s patients in fact saw a horizontal row of discrete segments. If an attentional bias favouring right-sided objects and penalising left-sided stimuli is at work in neglect, then right-sided segments were likely to attract patients' attention. In keeping with our present results, attentional bias could have influenced patients' perceptual judgement about the centre of the lines, for example by pushing rightward the candidate segment or the interval between segments to be chosen to mark the transaction. If so, increasing the number of segments (as in the illusory 'longer' lines) would increase the number of right-sided 'attractors', thus increasing the probability of making a greater rightward error in bisection.

While it is certainly possible that the concept of attention can ultimately be reduced to that of internal dynamics of representation (Bisiach, 1993), the modalities and processes

\footnotetext{
${ }^{1}$ Interestingly, computational models of line bisection also suggest an important role of competition between portions of the line in shaping normal and pathological performance on this task (Anderson, 1996; Mozer, Halligan, \& Marshall, 1997).
} 
of this reduction remain to be spelt out. Our results indicate that currently available models of selective attention, with their emphasis on competition for selection (Desimone \& Duncan, 1995), may provisionally offer a suitable framework to interpret significant aspects of neglect patients' behaviour.

\section{Acknowledgements}

We thank Emmanuelle Lacaze for help in testing patients.

\section{References}

Anderson, B. (1996). A mathematical model of line bisection behaviour in neglect. Brain, 119, 841-850.

Anderson, B., Mennemeier, M., \& Chatterjee, A. (2000). Variability not ability: Another basis for performance decrements in neglect. Neuropsychologia, 38, 785-796.

Bartolomeo, P., \& Chokron, S. (1999). Egocentric frame of reference: Its role in spatial bias after right hemisphere lesions. Neuropsychologia, 37, 881-894.

Bartolomeo, P., \& Chokron, S. (2001). Levels of impairment in unilateral neglect. In F. Boller, \& J. Grafman (Eds.), Handbook of neuropsychology (Vol. 4, pp. 67-98). Amsterdam: Elsevier.

Bartolomeo, P., \& Chokron, S. (2002). Orienting of attention in left unilateral neglect. Neuroscience and Biobehavioral Reviews, 26, 217234.

Bartolomeo, P., D'Erme, P., \& Gainotti, G. (1994). The relationship between visuospatial and representational neglect. Neurology, 44, $1710-1714$.

Bartolomeo, P., D'Erme, P., Perri, R., \& Gainotti, G. (1998). Perception and action in hemispatial neglect. Neuropsychologia, 36, 227-237.

Bartolomeo, P., Siéroff, E., Chokron, S., \& Decaix, C. (2001). Variability of response times as a marker of diverted attention. Neuropsychologia, 39, 358-363.

Barton, J. J., \& Black, S. E. (1998). Line bisection in hemianopia. Journal of Neurology, Neurosurgery and Psychiatry, 64, 660-662.

Bisiach, E. (1993). Mental representation in unilateral neglect and related disorders. The Quarterly Journal of Experimental Psychology, 46A, 435-461.

Bisiach, E., Bulgarelli, C., Sterzi, R., \& Vallar, G. (1983). Line bisection and cognitive plasticity of unilateral neglect of space. Brain and Cognition, 2, 32-38.

Bisiach, E., Capitani, E., Luzzatti, C., \& Perani, D. (1981). Brain and conscious representation of outside reality. Neuropsychologia, 19, 543551.

Bisiach, E., \& Luzzatti, C. (1978). Unilateral neglect of representational space. Cortex, 14, 129-133.

Bisiach, E., Pizzamiglio, L., Nico, D., \& Antonucci, G. (1996). Beyond unilateral neglect. Brain, 119, 851-857.

Butter, C. M., Rapcsak, S., Watson, R. T., \& Heilman, K. M. (1988). Changes in sensory inattention. Neuropsychologia, 26, 533-545.

Chatterjee, A. (2002). Spatial anisometry and representational release in neglect. In H. O. Karnath, D. Milner, \& G. Vallar (Eds.), The cognitive and neural bases of spatial neglect (pp. 167-180). Oxford: Oxford University Press.

Chatterjee, A., Thompson, K. A., \& Ricci, R. (1999). Quantitative analysis of cancellation tasks in neglect. Cortex, 35, 253-565.

Chokron, S., Bernard, J. M., \& Imbert, M. (1997). Length representation in normal and neglect subjects with opposite reading habits studied through a line extension task. Cortex, 33, 47-64.

Chokron, S., Colliot, P., Bartolomeo, P. The role of vision on spatial representations. Cortex, in press.
Daini, R., Angelelli, P., Antonucci, G., Cappa, S. F., \& Vallar, G. (2002). Exploring the syndrome of spatial unilateral neglect through an illusion of length. Experimental Brain Research, 144, 224-237.

De Renzi, E., Gentilini, M., Faglioni, P., \& Barbieri, C. (1989). Attentional shifts toward the rightmost stimuli in patients with left visual neglect. Cortex, 25, 231-237.

D'Erme, P., De Bonis, C., \& Gainotti, G. (1987). Influenza dell'emi-inattenzione e dell'emianopsia sui compiti di bisezione di linee nei pazienti cerebrolesi. Archivio di Psicologia, Neurologia e Psichiatria, 48, 165-189.

D’Erme, P., Robertson, I., Bartolomeo, P., Daniele, A., \& Gainotti, G. (1992). Early rightwards orienting of attention on simple reaction time performance in patients with left-sided neglect. Neuropsychologia, 30, 989-1000.

Desimone, R., \& Duncan, J. (1995). Neural mechanisms of selective visual attention. Annual Review in Neurosciences, 18, 193-222.

Doricchi, F., \& Angelelli, P. (1999). Misrepresentation of horizontal space in left unilateral neglect: Role of hemianopia. Neurology, 52, 18451852.

Driver, J., \& Husain, M. (2002). The role of spatial working memory deficits in pathological search by neglect patients. In H. O. Karnath, D. Milner, \& G. Vallar (Eds.), The cognitive and neural bases of spatial neglect (pp. 351-62). Oxford: Oxford University Press.

Fuchs, W. (1920). Untersuchung über das Sehen der Hemianopiker und Hemiamblyopiker. Zeitschrift für Psychologie und Physiologie Sinnersorganen, 84, 67-169.

Gainotti, G., D’Erme, P., \& Bartolomeo, P. (1991). Early orientation of attention toward the half space ipsilateral to the lesion in patients with unilateral brain damage. Journal of Neurology, Neurosurgery and Psychiatry, 54, 1082-1089.

Gauthier, L., Dehaut, F., \& Joanette, Y. (1989). The bells test: A quantitative and qualitative test for visual neglect. International Journal of Clinical Neuropsychology, 11, 49-53.

Halligan, P. W., \& Marshall, J. C. (1989). Is neglect (only) lateral? A quadrant analysis of line cancellation. Journal of Clinical and Experimental Neuropsychology, 11, 793-798.

Halligan, P. W., \& Marshall, J. C. (1991). Spatial compression in visual neglect: A case study. Cortex, 27, 623-629.

Halligan, P. W., \& Marshall, J. C. (1998). Visuospatial neglect: The ultimate deconstruction? Brain and Cognition, 37, 419-438.

Halligan, P. W., Marshall, J. C., \& Wade, D. T. (1990). Do visual field deficits exacerbate visuo-spatial neglect? Journal of Neurology, Neurosurgery and Psychiatry, 53, 487-491.

Heilman, K. M., Bowers, D., Coslett, H. B., Whelan, H., \& Watson, R. T. (1985). Directional hypokinesia: Prolonged reaction times for leftward movements in patients with right hemisphere lesions and neglect. Neurology, 35, 855-859.

Heilman, K. M., Watson, R. T., \& Valenstein, E. (2002). Spatial neglect. In H. O. Karnath, D. Milner, \& G. Vallar (Eds.), The cognitive and neural bases of spatial neglect (pp. 3-30). Oxford: Oxford University Press.

Hoffman, J. E., \& Subramaniam, B. (1995). The role of visual attention in saccadic eye movements. Perception and Psychophysics, 57, 787-795.

Kerkhoff, G. (2000). Spatial hemineglect in humans. Progress in Neurobiology, 63, 1-27.

Kinsbourne, M. (1970). A model for the mechanism of unilateral neglect of space. Transactions of the American Neurological Association, 95, 143-146.

Kinsbourne, M. (1993). Orientational bias model of unilateral neglect: Evidence from attentional gradients within hemispace. In I. H. Robertson, \& J. C. Marshall (Eds.), Unilateral neglect: Clinical and experimental studies (pp. 63-86). Hove (UK): Lawrence Erlbaum Associates.

Kowler, E., Anderson, E., Dosher, B., \& Blaser, E. (1995). The role of attention in the programming of saccades. Vision Research, 35, 18971916.

Mark, V. W., \& Heilman, K. M. (1997). Diagonal neglect on cancellation. Neuropsychologia, 35, 1425-1436. 
Mark, V. W., Kooistra, C. A., \& Heilman, K. M. (1988). Hemispatial neglect affected by non-neglected stimuli. Neurology, 38, 640643.

Marshall, J. C., \& Halligan, P. W. (1989). Does the midsagittal plane play any privileged role in "left" neglect? Cognitive Neuropsychology, 6, 403-422.

Mattingley, J. B., Bradshaw, J. L., \& Phillips, J. G. (1992). Impairments of movement initiation and execution in unilateral neglect. Brain, 115, 1849-1874.

Mattingley, J. B., Husain, M., Rorden, C., Kennard, C., \& Driver, J. (1998). Motor role of human inferior parietal lobe revealed in unilateral neglect patients. Nature, 392, 179-182.

Milner, A. D. (1987). Animal models for the syndrome of spatial neglect. In M. Jeannerod (Ed.), Neurophysiological and neuropsychological aspects of spatial neglect (pp. 148-77). Amsterdam: Elsevier.

Milner, A. D., \& Harvey, M. (1995). Distortion of size perception in visuospatial neglect. Current Biology, 5, 85-89.

Mozer, M. C., Halligan, P. W., \& Marshall, J. C. (1997). The end of the line for a brain-damaged model of unilateral neglect. Journal of Cognitive Neuroscience, 9, 171-190.

Posner, M. I., Walker, J. A., Friedrich, F. J., \& Rafal, R. D. (1984). Effects of parietal injury on covert orienting of attention. Journal of Neuroscience, 4, 1863-1874.

Previc, F. H. (1990). Functional specialization in the lower and upper visual fields in humans: Its ecological origins and neurophysiological implications. Behavioral and Brain Sciences, 13, 519542 .
Prinzmetal, W., Amiri, H., Allen, K., \& Edwards, T. (1998). The phenomenology of attention. Part 1. Color, location, orientation, and "clarity". Journal of Experimental Psychology: Human Perception and Performance, 24, 261-282.

Prinzmetal, W., Nwachuku, I., Bodanski, L., Blumenfeld, L., \& Shimizu, N. (1997). The phenomenology of attention. Part 2. Brightness and contrast. Consciousness and Cognition, 6, 372-412.

Prinzmetal, W., \& Wilson, A. (1997). The effect of attention on phenomenal length. Perception, 26, 193-205.

Ricci, R., Calhoun, J., \& Chatterjee, A. (2000). Orientation bias in unilateral neglect: Representational contributions. Cortex, 36, 671-677.

Rousseaux, M., Beis, J. M., Pradat-Diehl, P., Martin, Y., Bartolomeo, P., Chokron, S., Leclercq, M., Louis-Dreyfus, A., Marchal, F., Pérénnou, D., Prairial, C., Samuel, C., Siéroff, E., Wiart, L., \& Azouvi, P. (2001). Normalisation d'une batterie de dépistage de la négligence spatiale. Etude de l'effet de l'âge, du niveau d'éducation, du sexe, de la main et de la latéralité [Presenting a battery for assessing spatial neglect. Norms and effects of age, educational level, sex, hand and laterality]. Revue Neurologique, 157, 1385-1401.

Shepherd, M., Findlay, J. M., \& Hockey, R. J. (1986). The relationship between eye movements and spatial attention. The Quarterly Journal of Experimental Psychology, 38A, 475-791.

Vallar, G. (1998). Spatial hemineglect in humans. Trends in Cognitive Sciences, 2, 87-97.

Werth, R., \& Poppel, E. (1988). Compression and lateral shift of mental coordinate systems in a line bisection task. Neuropsychologia, 26, $741-745$. 